\title{
Comparative Morphology of the Hemolymph Vascular System in Scorpions-A Survey Using Corrosion Casting, MicroCT, and 3D-Reconstruction
}

\author{
Christian S. Wirkner ${ }^{1 *}$ and Lorenzo Prendini ${ }^{2}$ \\ ${ }^{1}$ Institut für Spezielle Zoologie und Evolutionsbiologie, Friedrich-Schiller-Universität Jena, Erbertstr. 1, \\ Jena 07743, Germany \\ ${ }^{2}$ Division of Invertebrate Zoology, American Museum of Natural History, New York, New York 10024
}

\begin{abstract}
Although scorpions are one of the better known groups of Arthropoda, detailed knowledge of their anatomy remains superficial. This contribution presents the first comprehensive investigation of the gross morphology of the scorpion vascular system, based on a survey of species representing all major lineages of the order, using classical and modern non-destructive techniques in combination with three-dimensional reconstruction. The investigation reveals that the hemolymph vascular system (HVS) of Scorpiones comprises a central pumping heart which extends the entire length of the mesosoma and is enclosed in a pericardium. Several arteries branch off the heart to supply different organs and body regions. Two different anterior aorta major branching patterns are identified among the species investigated. Arteries that branch off the anterior aorta system supply the appendages (chelicerae, pedipalps, and walking legs) and the central nerve mass with a complex arterial network. This study of the HVS of scorpions provides further evidence that the vascular systems of euarthropods can be highly complex. Use of the term "open circulatory system" within arthropods is re-emphasized, as it refers to the general organization of the body cavity (i.e. mixocoely) rather than to the complexity of the circulatory system. J. Morphol. 268:401-413, 2007. @ 2007 Wiley-Liss, Inc.
\end{abstract}

KEY WORDS: Scorpiones; circulatory organs; heart; cardiac

Scorpions are one of the best known groups of arthropods. Nonetheless, their phylogenetic relationships are only now beginning to be solved, although a number of studies exist to date (e.g., Stockwell, 1989; Prendini, 2000; Soleglad and Fet, 2003). The same applies to their morphology, despite numerous studies from the classical period of morphology in the 19th Century, our knowledge of the detailed structure of the internal organ systems is still superficial.

The first comprehensive account of the circulatory system of Scorpiones was provided by Newport (1843). Newport's schematic drawing of a sagittal section of a scorpion, illustrating all major organ systems, was so influential that it was subsequently recycled several times in literature on the anatomy of scorpions (e.g., Ch'en-Pin, 1940; Gruner, 1993).
Later studies that attempted to provide a comparative assessment of this organ system only examined a few species (e.g., Schneider, 1892; Petrunkevitch, 1922; Dubuisson, 1925). Other workers concentrated on details of histology (e.g., Pawlowsky, 1922) or ultrastructure (e.g., Tjønneland et al., 1985), or focused only on specific parts of the organ system, e.g., the heart or the prosomal arteries (e.g., Randall, 1966; Locket, 2001). Textbook accounts of the morphology of the circulatory system are especially superficial as only the major arteries have been described to date, providing a simplistic picture of what is in reality a very complex arterial system (e.g., Farley, 1999). The best known aspect of the circulatory system is the structure (gross anatomy, histology, and ultrastructure) of the heart and its associated structures (e.g., Randall, 1966; Tjønneland et al., 1985). The morphology of the arterial system connected to the anterior aorta in the prosoma is poorly known, as is the arterial system of the opisthosoma. In summary, although several detailed studies of the circulatory organs of scorpions have been conducted, major components of the organ system have only been studied superficially, and an analysis of the system across the major groups of scorpions remains to be presented.

In this study, we present the first comparative overview of the morphology of the scorpion circulatory system, focusing on the gross morphology of the heart and major arterial systems, based on a study of exemplars selected from most major lineages of Scorpiones, using modern techniques for visualizing fine arteries. Our methods include a combination of corrosion-casting techniques, Microcomputer-tomography, and computer aided 3Dreconstruction, supplemented with classical semi-

\footnotetext{
*Correspondence to: Christian S. Wirkner, Institut für Spezielle Zoologie und Evolutionsbiologie, Friedrich-Schiller-Universität Jena, Erbertstr. 1, Jena 07743, Germany.

E-mail: christian.wirkner@web.de
}

Published online 19 March 2007 in

Wiley InterScience (www.interscience.wiley.com)

DOI: 10.1002/jmor.10512 
thin sectioning methods, to allow a higher degree of resolution (see also Wirkner and Richter, 2004).

\section{MATERIALS AND METHODS Taxon Sample}

Scorpion phylogenetic research is controversial. Only a few higher-level cladistic analyses have been published thus far, and authors disagree on methods and approaches (e.g., Lamoral, 1980; Stockwell, 1989; Prendini, 2000; Soleglad and Fet, 2003; Prendini and Wheeler, 2005). All workers agree, however, that Buthidae (Buthoidea) form the sister-group of the remaining, "non-buthid" families (Coddington et al., 2004). Two major clades can be distinguished in the non-buthid lineage, the Scorpionoidea and (Chactoidea + Vaejovoidea), although (Chactoidea + Vaejovoidea) may be paraphyletic with respect to Scorpionoidea, the monophyly of which is well-established. Therefore, to obtain an overview of the main scorpion taxa for the present study, five species of Buthidae (representing both major clades within the family; marked as bold in Table 1), a species of Diplocentridae (Scorpionoidea), and a species of Iuridae (Vaejovoidea) were studied in detail (also marked bold in Table 1). Further 20 species, selected from the families Chactidae, Liochelidae, Scorpionidae, Superstitioniidae, and Vaejovidae were screened for comparison (also listed in Table 1).

\section{Histology}

Specimens were dissected and fixed in Bouin's fixative, dehydrated in ethanol and, after an intermediate step of epoxypro- pane, embedded in Araldit epoxy resin under vacuum. Serial semi-thin sections $(1-1.5 \mu \mathrm{m})$ were prepared with a Microm HM 360 ultramicrotome using glass or diamond knifes, and stained with a mixture of $1 \%$ azure II and $1 \%$ methylene blue in an aqueous $1 \%$ borax solution for $\sim 30 \mathrm{~s}$ at $80-90^{\circ} \mathrm{C}$.

\section{Corrosion Casting}

Acrylic casting resin Mercox CL-2R/2B (Vilene Comp. Ltd, Tokyo, Japan) was injected into the heart of ether-anesthetized specimens to prepare casts of the circulatory system. Before injecting, the resin was mixed with approximately $0.05 \mathrm{mg}$ MA initiator and placed in a $5 \mathrm{ml}$ syringe. Micropipettes (Hilsberg pipettes, diameter $1.0 \mathrm{~mm}$, thickness $0.2 \mathrm{~mm}$; pulled with a KOPF Puller 720) used for injecting were filled using the syringe. The pipettes were placed on an adjustable instrument holder in a mechanical micromanipulator and the tips inserted through the intersegmental membrane between the mesosomal tergites directly into the vascular system, i.e. the heart. The resin was then injected and the specimens left for several minutes to allow polymerization and tempering of the resin. Specimens destined for the MicroCT were fixed in Bouin's fixative and then critical point dried (BAL-TEC CPD 030). Alternatively, specimens were macerated for 1-2 days by repeated immersion in $10 \%$ potassium hydroxide at ambient temperature, followed by washing in a solution of $2 \mathrm{~g}$ Pepsin in $10 \mathrm{ml}$ of $2 \% \mathrm{HCl}$ (Hilken, 1994).

\section{MicroCT}

X-ray imaging was performed with a SkyScan-1072 High-resolution MicroCT system in high resolution mode. See Wirkner and Richter (2004) for details of settings.

TABLE 1. List of species in which circulatory system has been studied here and in the literature

\begin{tabular}{|c|c|c|c|c|}
\hline Superfamily & Family & Species & Structure & Reference \\
\hline \multirow{12}{*}{ Buthoidea } & \multirow{12}{*}{ Buthidae } & Androctonus amoreuxi (Audouin, 1826) & AP1 & This study \\
\hline & & Androctonus australis (Linnaeus, 1758) & AP1 & This study \\
\hline & & Androctonus bicolor Ehrenberg, 1828 & AP1 & This study \\
\hline & & Babycurus jacksoni (Pocock, 1890) & AP1 & This study \\
\hline & & Buthacus arenicola (Simon, 1885) & AP1 & This study \\
\hline & & Buthus occitanus (Amoreux, 1789) & AP2 & Schneider, 1892 \\
\hline & & Centruroides exilicauda (Wood, 1863) & AP1 & This study \\
\hline & & Centruroides insulanus (Thorell, 1876) & AP1 & Petrunkevitch, 1922 \\
\hline & & Leiurus quinquestriatus (Ehrenberg, 1828) & AP1 & This study \\
\hline & & Lychas mucronatus (Fabricius, 1798) & AP1 & This study \\
\hline & & Mesobuthus martensii (Karsch, 1879) & AP1 & This study \\
\hline & & Parabuthus leiosoma (Ehrenberg, 1828) & AP1 & This study \\
\hline \multirow[t]{2}{*}{ Chactoidea } & Chactidae & Brotheas granulatus Simon, 1877 & AP2 & This study \\
\hline & Euscorpiidae & Euscorpius sp. & AP2 & Schneider, 1892 \\
\hline \multirow[t]{10}{*}{ Scorpionoidea } & \multirow[t]{2}{*}{ Diplocentridae } & Diplocentrus spitzeri Stahnke, 1970 & AP2 & This study \\
\hline & & Diplocentrus lindo Stockwell and Baldwin, 2001 & AP2 & This study \\
\hline & \multirow[t]{2}{*}{ Liochelidae } & Iomachus politus Pocock, 1896 & AP2 & This study \\
\hline & & Opisthacanthus rugiceps Pocock, 1897 & AP2 & This study \\
\hline & \multirow[t]{3}{*}{ Scorpionidae } & Heterometrus laoticus Couzijn, 1981 & AP2 & This study \\
\hline & & Pandinus cavimanus (Pocock, 1888) & AP2 & This study \\
\hline & & Pandinus imperator (Koch, 1841) & AP2 & This study \\
\hline & \multirow[t]{3}{*}{ Urodacidae } & Urodacus armatus Pocock, 1888 & AP2 & Locket, 2001 \\
\hline & & Urodacus novaehollandiae Peters, 1861 & AP2 & Locket, 2001 \\
\hline & & Urodacus yaschenkoi (Birula, 1903) & AP2 & Locket, 2001 \\
\hline \multirow[t]{9}{*}{ Vaejovoidea } & \multirow[t]{2}{*}{ Iuridae } & Anuroctonus phaiodactylus Wood, 1863 & AP2 & This study \\
\hline & & Hadrurus arizonensis Ewing, 1928 & AP2 & This study \\
\hline & \multirow{7}{*}{ Vaejovidae } & Superstitionia donensis Stahnke, 1940 & AP1 & This study \\
\hline & & Paruroctonus silvestrii Borelli, 1909 & AP1 & This study \\
\hline & & Serradigitus subtilimanus (Stahnke, 1940) & AP1 & This study \\
\hline & & Serradigitus wupatkiensis (Stahnke, 1940) & AP1 & This study \\
\hline & & Smeringurus mesaensis (Stahnke, 1961) & AP1 & This study \\
\hline & & Uroctonus mordax Thorell, 1876 & AP1 & This study \\
\hline & & Vaejovis spinigerus (Wood, 1863) & AP1 & This study \\
\hline
\end{tabular}

Occurrence of anterior aorta major branching patterns (AP1 and AP2) are listed in column "structure" (see also discussion). Species in bold were investigated in detail for this study. 


\section{D Reconstruction}

Stacks of virtual sections produced by MicroCT were used for 3D-reconstructions in the software Imaris 4.0.5 (Fa. Bitplane). A scene was created in the program module "Surpass", the volume rendering function was chosen to visualize the entire data set, and the contours of organs studied were marked on every virtual cross section with a polygon. Stacks of polygons were visualized by surface renderings.

\section{Scanning Electron Microscopy}

Casts for scanning electron microscopy (SEM) were air-dried, coated with gold or palladium (BAL-TEC SCD 005), and studied using a SEM (LEO 1430). See Wirkner and Richter (2003) for details.

\section{Image Management}

Figures were arranged and prepared into plates using Corel Graphics Suite 11. Bitmap images were embedded into Corel Draw 11 files and digitally edited with Coral Photo Paint 11.

\section{RESULTS}

The following descriptions of the circulatory system follow the general morphological divisions, prosoma and opisthosoma, recognized in scorpions (Hjelle, 1990). The prosoma consists of nine segments and is dorsally covered by the carapace which bears one or more pairs of lateral and a pair of median ocelli. The opisthosoma is divided into a broad, anterior mesosoma, comprising seven segments, and a slender, tail-like metasoma (or cauda) comprizing five segments and the telson terminating in a sting (aculeus).

As in all arthropods, the scorpion circulatory system comprises a system of vascular structures combined with a complex system of sinuses and lacunae, in which the movements of other organs such as the gut and muscles propel hemolymph currents to some extent. The following detailed descriptions of the circulatory system focus mainly on the vascular part of this system (hemolymph vascular system, hereafter HVS). Measurements relating to internal vessel diameters are only approximate, as the size of muscular and connective tissues depend on their state of contraction and fixation.

The central nervous system of scorpions is concentrated in the prosoma and anterior mesosoma (nomenclature following Babu, 1965; Hjelle, 1990). The system consists of the following sections: supraesophageal nerve mass (brain); subesophageal nerve mass (thoracic nerve mass), connected to the brain by short, thick circumesophageal connectives; three free mesosomal ganglia; four metasomal ganglia; and connected nerves. The nerve masses comprise the neuropils and corresponding pericaria surrounding them (Fig. $4 \mathrm{~F} ; \mathrm{sgl}$ ).

\section{Buthidae}

The following description of the circulatory system of Buthidae is based on observations of the following species: Androctonus amoreuxi, Buthacus arenicola, Centruroides exilicauda, and Lychas mucronatus. Differences among these species are noted where necessary.

\section{Heart, Pericardial Sinus, and Associated Structures}

The dorsal vessel comprises the musculated and ostiated heart that is extended anteriorly by the anterior aorta and posteriorly by the posterior aorta. The anterior end of the spindle-shaped heart lies in the first mesosomal segment, the posterior end in the middle of the seventh mesosomal segment. The musculature of the heart comprises relatively thick, spirally-arranged muscle fibers. The heart is equipped with seven pairs of incurrent ostia distributed along its entire length (Figs. $1 \mathrm{~A}, 3 \mathrm{~A}$; os). The heart is suspended dorsally, laterally, and ventrally (Fig. 1B,F; li) to the body wall by seven groups of so-called ligaments (terminology after Petrunkevitch, 1922). The heart nerve is prominent and clearly identified as a cord extending along the dorsal surface of the heart (Fig. 1D; hn). The sac-like pericardium surrounds the entire heart (Fig. 1F; pc). Each book lung sinus is connected via a pulmono-pericardial sinus to the pericardium (Fig. 1F; ps). These sinuses are attached to the lateral cuticle (Fig. 1E; ps) and extend down to the four pairs of book lungs.

\section{Major Arterial Systems}

Several major arterial systems, including the cardiac arteries, and the anterior and posterior aortae, distribute hemolymph from the heart to different organs and regions of the body.

Eight pairs of segmental cardiac arteries emanate from the heart (Figs. 1C, 3A; ca1-8). The cardiac arteries exit the heart in a ventro-lateral position directly ventral to the ostia. The first pair of cardiac arteries emanates shortly posterior to the transition of the heart into the anterior aorta (Fig. 1C inset; ca1) but, as previously stated, no pair of ostia can be found in this region (compare Fig. 1A inset). Each artery is equipped with a valve at its origin. The cardiac arteries present a fine branching pattern and irrigate the organs and tissues in the mesosoma (Fig. 2A; ca1-3). The transition of the heart into the anterior aorta occurs at a point where the dorsal vessel passes the diaphragm (Fig. 1A,C; ao). Anterior to this point, the aorta descends obliquely toward the thin esophagus (Fig. 3B; oe). The anterior aorta is stout, with a diameter of ca. $500 \mu \mathrm{m}$ in Lychas mucronatus. 
The position of the anterior aorta system in relation to the cuticular structures of the prosoma can be seen in Figure 2B. The angle at which the aorta descends varies slightly in different species. For example, in Parabuthus leiosoma (Fig. 2C) the angle of descent is rather steep, whereas in $L$.
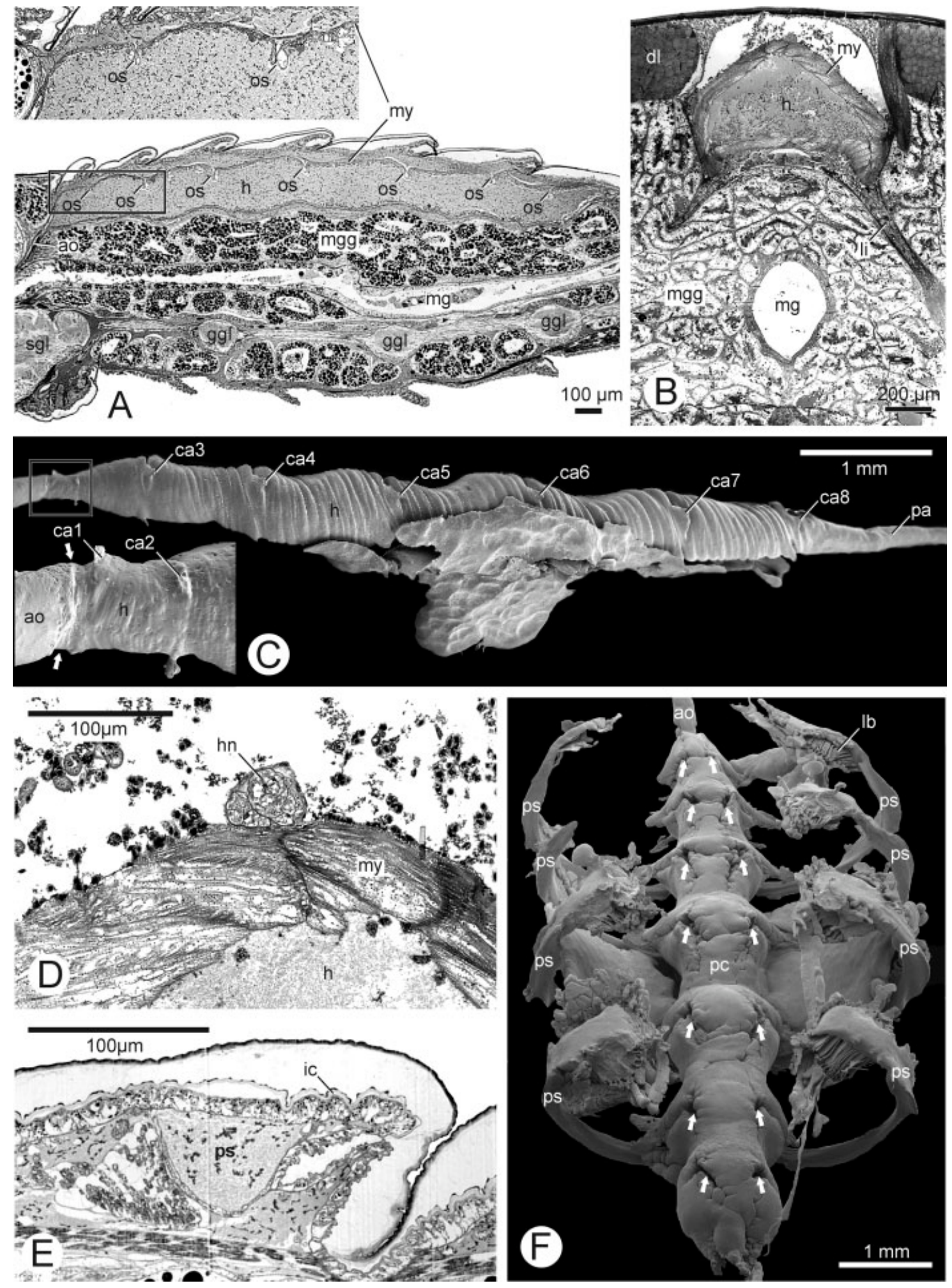

Figure 1 
mucronatus (Fig. 2D), it is more gradual. The aorta splits into two large trunks which extend laterally around the esophagus. Six pairs of major vessels split off the aorta before it merges into the ventral vessel (= supraneural vessel). These are the cheliceral arteries, pedipalpal arteries, and arteries for the four pairs of walking legs (pedal arteries). The cheliceral arteries form a lateral arch around the supraesophageal ganglion (brain) and continue dorsally into the chelicerae (Fig. 2C,D; ch). Two branches split off the main branches antero-lateral to the brain. One of these continues to the median eyes, whereas the other supplies muscles in the posterior prosoma (Fig. 2C,D; oa, sc). Several small vessels, supplying musculature and tissues in the prosoma, emanate from these arteries. The cheliceral arteries fork to supply the cheliceral musculature. The pedipalpal arteries are the largest vessels branching off the aorta at the bend of the aorta trunks (Figs. 2C,D, 3B-D; $\mathrm{pp})$. These arteries extend laterally around the esophageal commissures and into the pedipalps in proximity to the pedipalpal nerves. The pedal arteries extend straight into the corresponding legs from their origin at the aortic trunks. Along the way, these arteries produce several small vessels that supply the surrounding tissues (mainly musculature). The arteries for the first walking legs emanate from almost the same point as the pedipalpal arteries, or split off a short way along them, so that both possess a common trunk (Figs. 2C,D, 3B-D; I). After both aortic trunks have turned in a posterior direction, they produce three pairs of arteries for the second to fourth pair of walking legs (Figs. 2C,D, 3B-D; II, III, IV). Poste-

Fig. 1. Heart and associated structures of Buthidae. A: Sagittal semi-thin section through mesosoma of Centruroides exilicauda. Heart extends from first to last mesosomal segment. A pair of ostia occurs (os) in each segment. Inset illustrates anterior part of heart in higher magnification (anterior at left). B: Semi-thin cross-section through mesosomal segment of Buthacus arenicola. A pair of hypocardiac ligaments leading off the heart ventrally (li). C: Cast of heart of C. exilicauda. SEM. Eight pairs of cardiac arteries branch off heart ventro-laterally. Cardiac musculature is arranged spirally. Inset illustrates transition of heart into anterior aorta (arrows) and bases of first and second cardiac arteries (ca1 + ca2) (dorsal at top). D: Semithin section through heart nerve of $B$. arenicola. Heart nerve extends along dorsal side of heart. E: Parasagittal semi-thin section through mesosomal segment. Pulmono-pericaridal sinus attached to cuticle. Animal was fixed shortly before molting; therefore, new cuticle (ic) is visible as a folded membrane. F: Cast of pericardium and associated structures of C. exilicauda. SEM. Four pulmono-pericardial sinuses (ps) lead off sac-like pericardium (pc). Sites where hypocardial ligaments leave pericardium are visible (arrows). Note that lamellae of book lungs are also filled with resin (lb). ao, aorta; ca, cardiac artery; dl, dorsal longitudinal muscle; ggl, ganglion; h, heart; lb, lamellae of book lungs; li, ligament; mg, midgut; mgg, midgut gland; my, myocardium; os, ostium; pa, posterior aorta; pc, pericardium; ps, pulmono-pericardial sinus; sgl, subesophageal ganglion. rior to the point where the arteries for the fourth pair of walking legs branch off, the two trunks of the aorta bend inwards and unite to form the supraneural ventral vessel (Figs. 3A,B, 4A,C; vv). This vessel continues through the entire trunk, producing lateral arteries for the ganglia in each segment. The posterior aorta extends into the metasoma from the posterior end of the heart.

\section{Arterial Supply of Central Nervous System}

The central nervous system in the prosoma, i.e., the supra- and subesophageal ganglion masses, is supplied by a network of vessels branching off the major arteries of the anterior aorta. The posteriorly-directed parts of the two aortic trunks are connected medially by five vessels. In the midline of the body, an artery emanates ventrally from each of these connections, and continues down through the thoracic nerve mass (Fig. 3C,D; tgl). These arteries are therefore termed transganglionic arteries (Figs. 2F, 4A; asterisks; Fig. 4F; tgl). Another four transganglionic arteries emanate from the anterior part of the ventral vessel, shortly after the two trunks of the aorta unite (Fig. 4A; last four asterisks). Each transganglionic artery descends vertically between neighboring neuromeres of the subesophageal nerve mass (Fig. $4 \mathrm{~F}$; tgl) before branching laterally at the border of the neuropils and the pericaria. These capillaries spread through the neuropiles and display a complex branching pattern (see Fig. 4C,D; meshwork of small arteries). The supply of the nerve masses is supplemented by small vessels branching off the cheliceral, pedipalpal, and pedal arteries (Fig. 4C,D; small arteries branching off pedal arteries IIV). Together, these transganglionic and intraganglionic arteries form a dense meshwork of small arteries in the central nerve masses. Anterior to the thoracic nerve mass, anterior intraganglionic arteries unite and form two parallel vessels termed peribuccal vessels (Fig. 4B; pb). These vessels are medially interconnected and their dorsal branches merge with the cheliceral arteries of either side, whereas the ventral branches run parallel to the cheliceral arteries into the anterior part of the prosoma.

\section{Iuridae and Diplocentridae}

The circulatory system of two "non-buthid" scorpions, Hadrurus arizonensis arizonensis (Iuridae) and Diplocentrus lindo (Diplocentridae), is compared below with the system described earlier for the Buthidae. Only major details and notable differences from the buthid circulatory system are described, to avoid redundancy. 

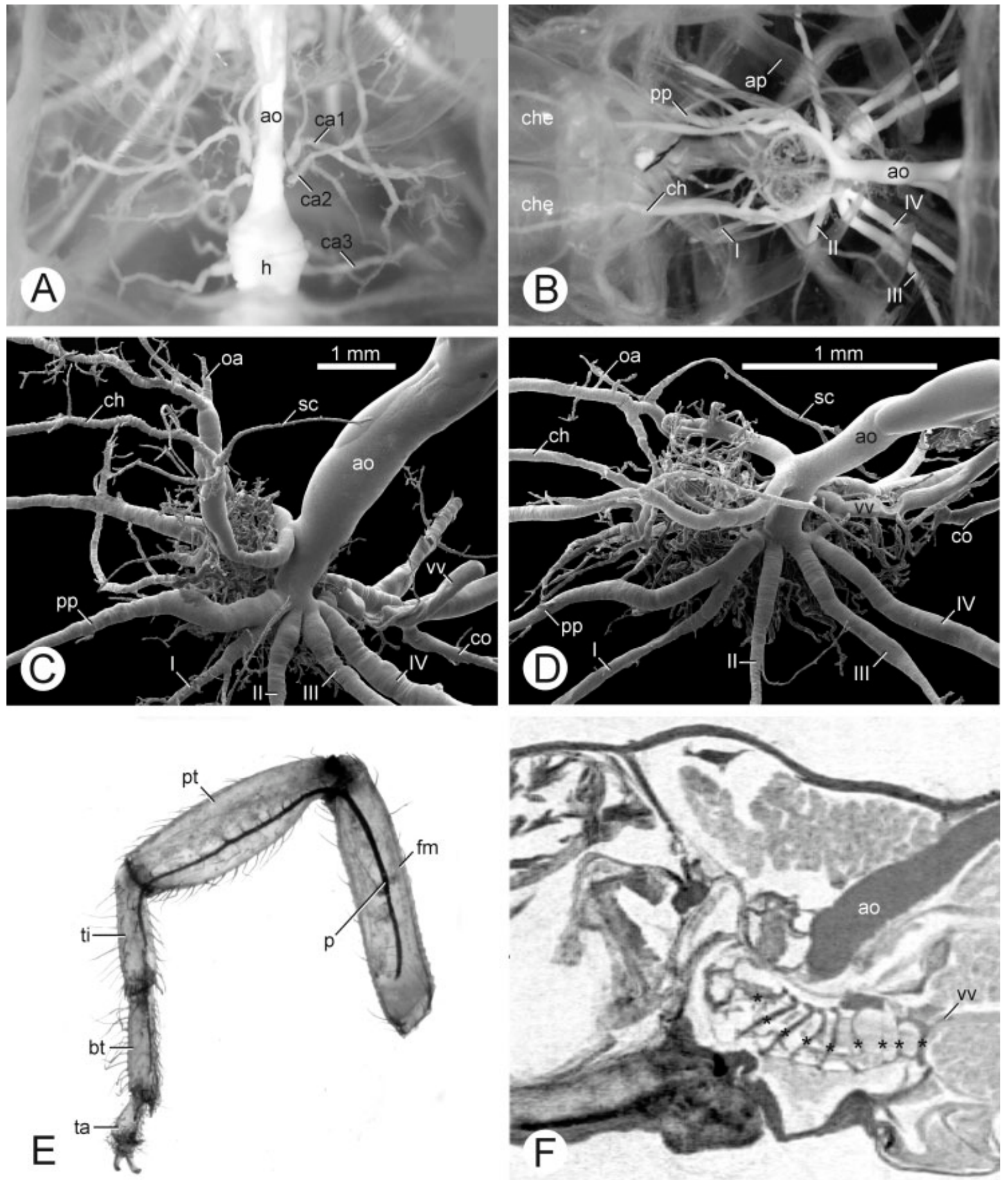

Fig. 2. Anterior aorta system of Buthidae. A: Photograph of cast of Lychas mucronatus. Soft tissues are dissolved and carapace removed to assist visualization of cast. Transition of heart into anterior aorta (ao) and first three pairs of cardiac arteries (ca) are visible (anterior at top). B: Photograph of cast of L. mucronatus. Soft tissues are dissolved and carapace removed to assist visualization of cast. Position of anterior aorta system (ao) in prosoma is visible in relation to cuticular structures, e.g. apodemes of walking legs (ap) (anterior at left). C: Cast of anterior aorta system of Androctonus amoreuxi. SEM. D: Cast of anterior aorta system of L. mucronatus. SEM. E: Cast of leg of Parabuthus leiosoma. Pedal artery is filled to tip of basitarsus (bt). Small vessels branch off leg artery mainly in patella (pt). F: Virtual sagittal MicroCT section through prosoma of Buthacus arenicola. Aorta descends in prosoma. Nine transganglionic arteries (asterisks) are discernible: first five emanate from commissural arteries, last four from anterior part of supraneural vessel. ao, aorta; ap, leg apodeme; bt, basitarus; ca, cardiac artery; ch, cheliceral artery; che, chelicera; co, coxa; fm, femur; h, heart; I-IV, pedal arteries I to IV; oa, optical artery; p, pedal artery; pp, pedipalpal artery; pt, praetarsus; sc, supracerebral artery; ta, tarsus; ti, tibia; vv, ventral vessel. 


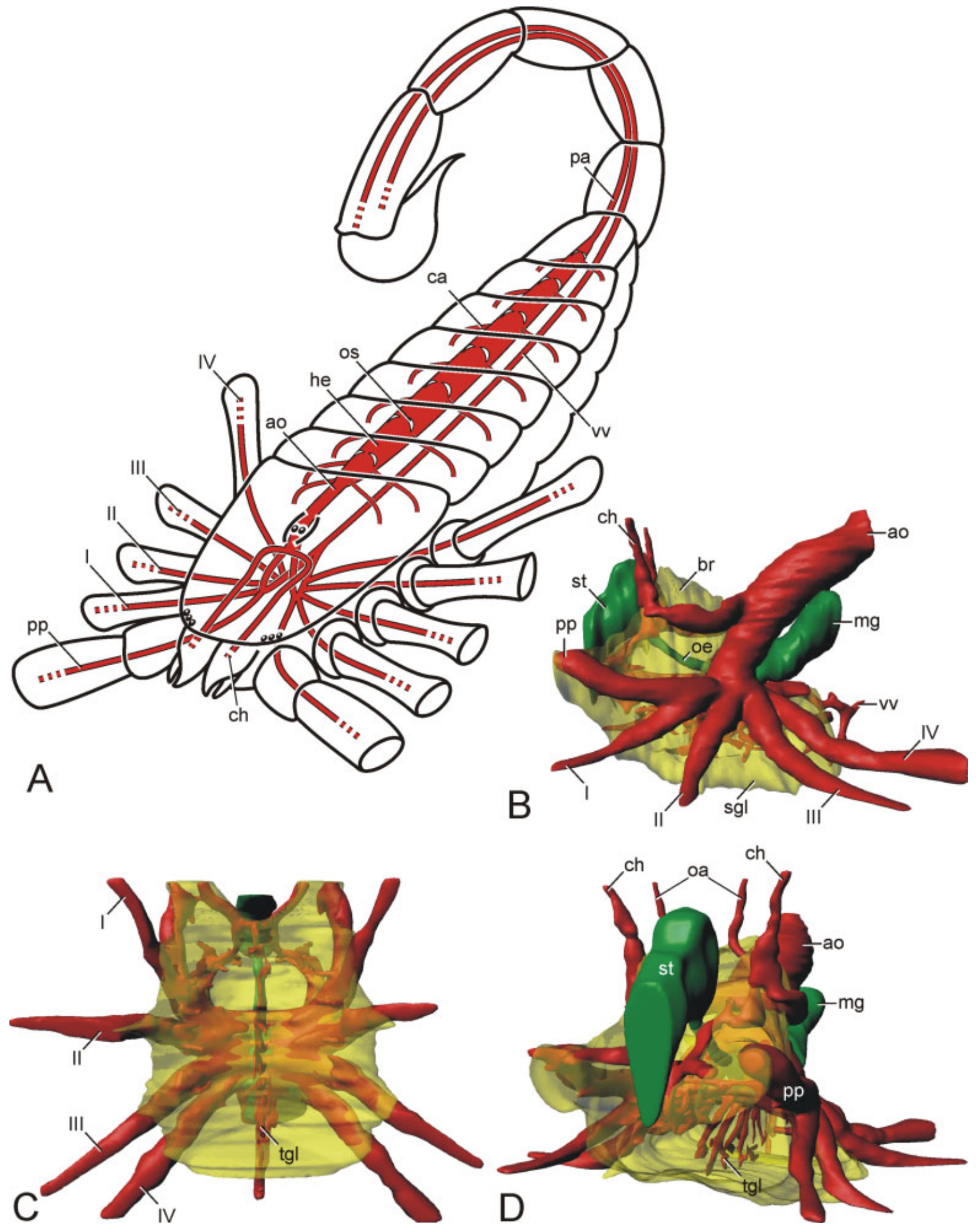

Fig. 3. 3D-reconstructions of hemolymph vascular system (HVS) of Scorpiones. A: Schematic diagram of major HVS of Scorpiones. B-D: Surface renderings of MicroCT scan of Buthacus arenicola (see Fig. 2F) showing major organ systems in prosoma. Color codes: red, HVS; green, digestive system; translucent yellow, CNS. B: Lateral aspect. C: Ventral aspect (anterior at top). D: Oblique anterior aspect. ao, aorta; br, brain; ca, cardiac artery; ch, cheliceral artery; he, heart; I-IV, pedal arteries I-IV; mg, midgut; oa, optical artery; oe, esophagus; os, ostium; pa, posterior aorta; pp, pedipalpal artery; sgl, subesophageal ganglion; st, stomach; tgl, transganglionic artery; vv, ventral vessel. 

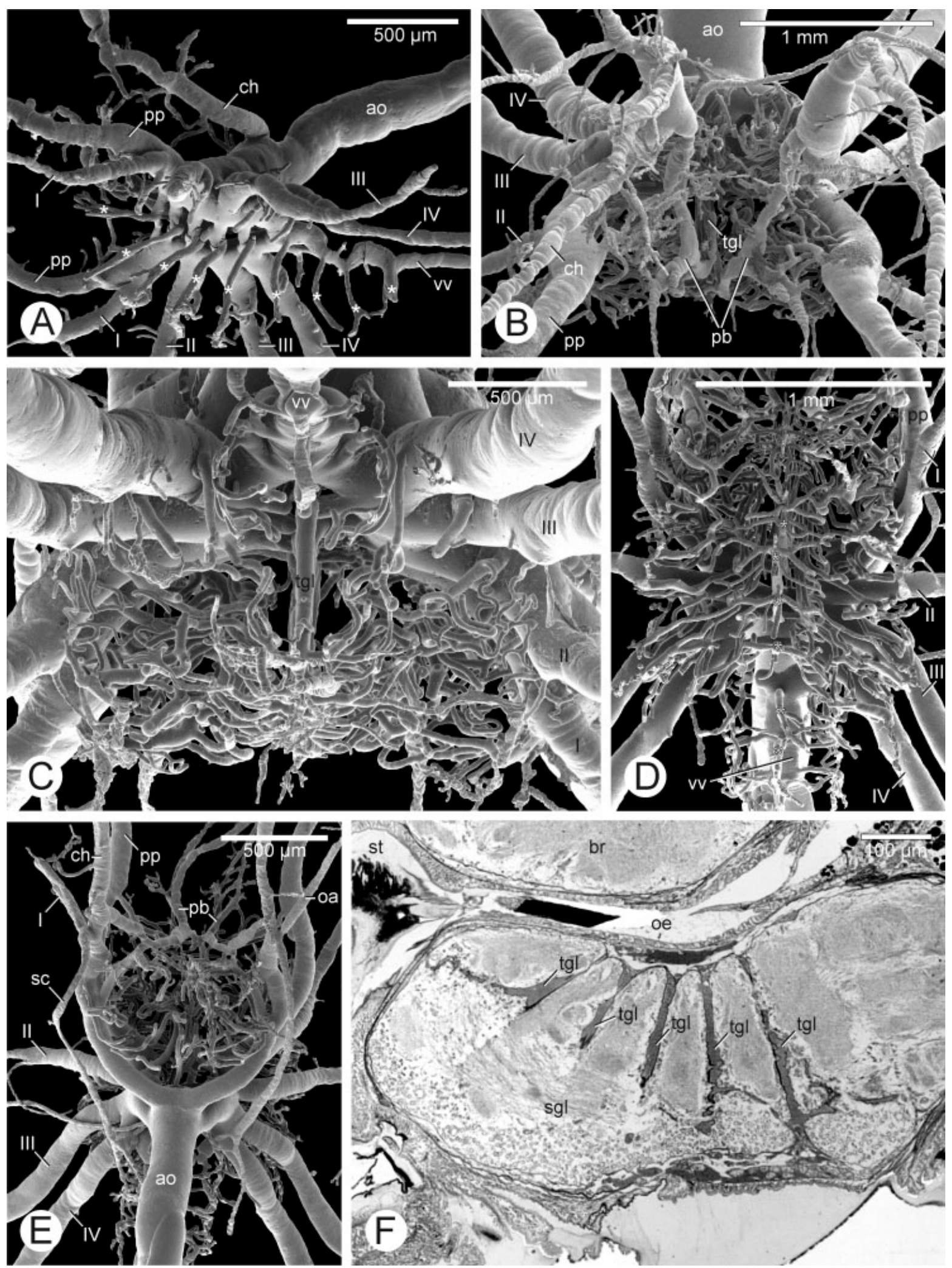

Fig. 4. Arterial supply of CNS of Buthidae. A: Cast of anterior aorta system of Centruroides exilicauda. SEM. Ventro-lateral aspect (anterior at left). Cast is incomplete as not all vessels were filled, providing view of transganglionic arteries (asterisks). B, C: Casts of anterior aorta system of Androctonus amoreuxi. SEM. B: Anterior aspect. Note dense meshwork of small arteries inside central nerve masses. C: Posterior aspect. D, E: Casts of anterior aorta system of Lychas mucronatus. SEM. D: Ventral aspect. E: Dorsal aspect. F: Sagittal semi-thin section through central nerve masses of C. exilicauda (anterior at left). ao, aorta; br, brain; ch, cheliceral artery; I-IV, pedal arteries I-IV; oa, optical artery; oe, esophagus; pa, posterior aorta; pb, peribuccal artery; sc, supracerebral artery; sgl, subesophageal ganglion; st, stomach; tgl, transganglionic artery; vv, ventral vessel. 

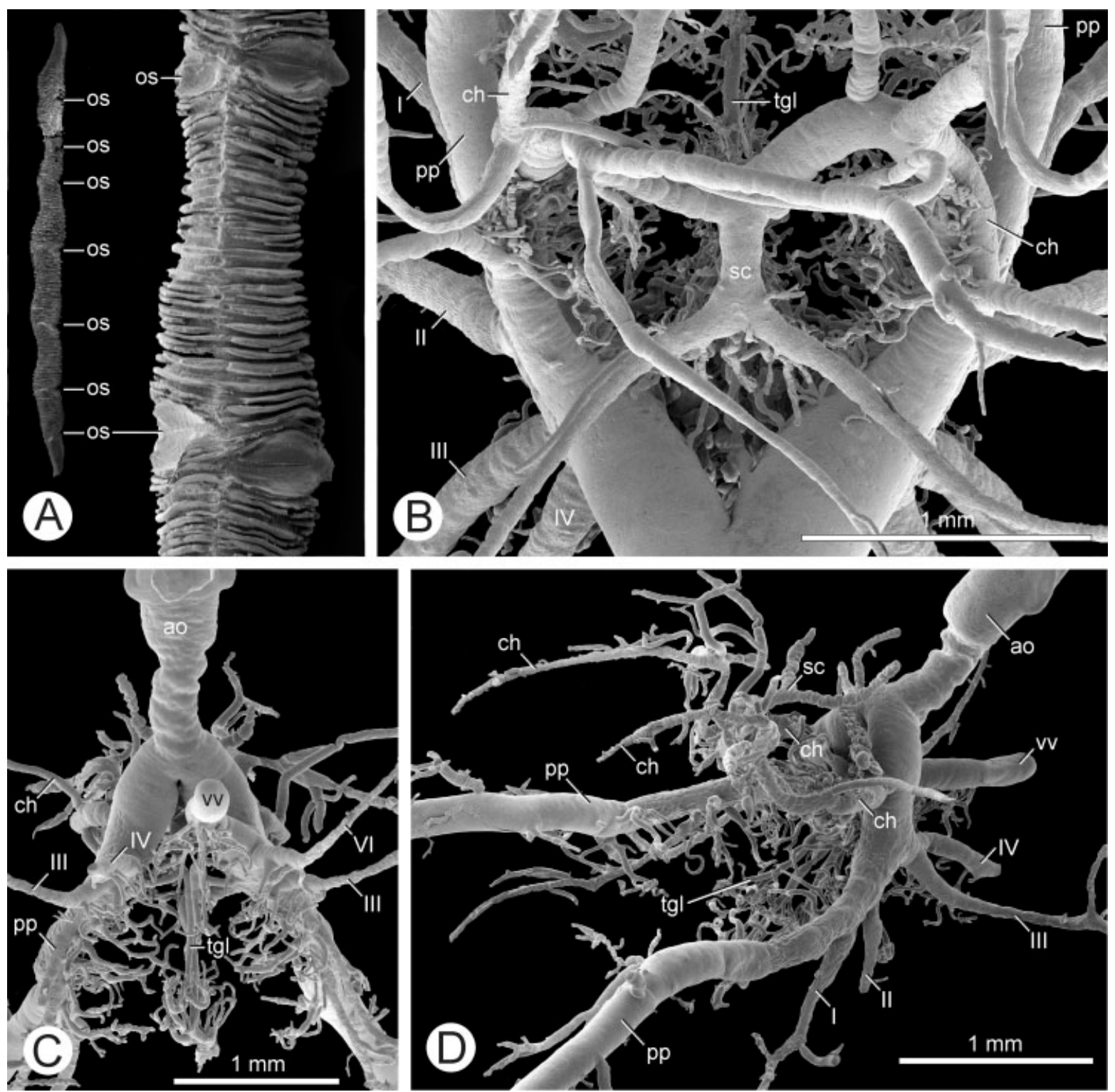

Fig. 5. HVS of Iuridae and Diplocentridae. A: Cast of heart of Hadrurus arizonensis arizonensis. SEM. Left side: complete heart (anterior at top). Right side: detail of heart showing two pairs of ostia. Note fissure in midline where semicircular muscle fibers meet. B: Cast of anterior aorta system of $H$. a. arizonensis (anterior at top). SEM. Note asymmetry of cheliceral arteries. C, D: Cast of anterior aorta system of Diplocentrus lindo. SEM. C: Posterior aspect. Transganglionic arteries bend back distally into central nerve mass. D: Antero-lateral aspect. Trunks of aorta continue as pedipalpal arteries. ao, aorta; ch, cheliceral artery; I-IV, pedal arteries I-IV; os, ostium; pp, pedipalpal artery; sc, supracerebral artery; tgl, transganglionic artery; vv, ventral vessel.

\section{Heart, Pericardial Sinus, and Associated Structures}

As in the buthid species described earlier, the heart of Hadrurus arizonensis arizonensis and Diplocentrus lindo extends from the first tergite to the seventh tergite, and is equipped with seven pairs of incurrent ostia, distributed along its entire length (Fig. 5A; os). Muscle fibers of the myocardium protrude into the lumen of the heart, especially in $H$. a. arizonensis (Fig. 5A). The cast shows that these fibers are semicircular and attach to one another in the midline of the heart. The pericardium encloses the complete heart. Hemolymph enters the pericardium through four pairs of pulmono-pericardial sinuses in the third to sixth mesosomal segments.

\section{Major Arterial Systems}

Eight pairs of segmental cardiac arteries, an anterior aorta, and a posterior aorta emanate from the heart in Hadrurus arizonensis arizonensis and Dip- 

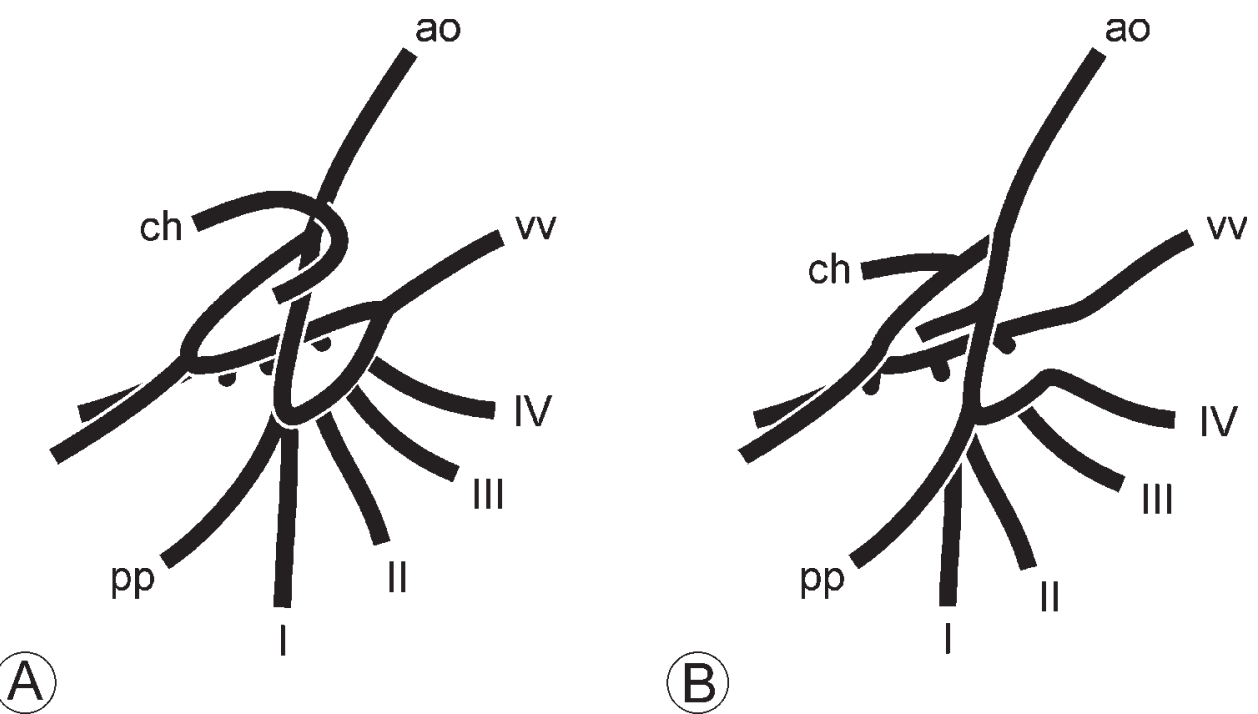

Fig. 6. Schematic diagram of two anterior aorta major branching patterns. A: Anterior Aorta Major Arterial Branching Pattern 1 (AP1). Cheliceral arteries share a common base (compare with Figs. 2C,D, 3A). Both aorta trunks bend backwards and unite as supraneural vessel (compare with Figs. 2D, 4A). See Table 1 and discussion for taxa in which observed. B: Anterior Aorta Major Arterial Branching Pattern 2 (AP2). Cheliceral arteries branch off two aorta trunks each (compare with Fig. 5B,D). Two aorta trunks merge into pedipalpal arteries (compare with Fig. 5B,D). Only one trunk of aorta continues as supraneural vessel (compare with Fig. 5C). ao, aorta; ch, cheliceral artery; I - IV, pedal arteries I to IV; pp, pedipalpal artery; vv, ventral vessel.

locentrus lindo. The cardiac arteries supply the organs in the mesosoma. The anterior aorta descends through the diaphragm slightly posterior to the brain. The cheliceral arteries branch off after the aorta divides and thus do not possess a common trunk (Fig. 5B,D; ch). They show asymmetry as to which regions they supply. One cheliceral artery divides into the cheliceral artery proper and another major trunk which bends posteriorly, dividing again to supply the postero-dorsal regions of the prosoma (Fig. 5B,D; sc) while the other cheliceral artery runs straight into the chelicerae, producing branches for the median eyes and the tissues in the anterior prosoma. Intraspecific variation occurs concerning which of the cheliceral arteries also supplies the posterodorsal prosoma. After the aorta divides, the aortic trunks merge directly into the pedipalpal arteries (Fig. 5D; pp). The first and second pedal arteries branch off the proximal part of the pedipalpal arteries. The third and fourth pedal arteries possess a common trunk branching off the aortic trunks posteriorly (Fig. 5D; I+II). The two aortic trunks do not unite, but one of the branches continues posteriorly as a ventral vessel directly above the ventral nerve cord (Fig. 5C; vv). Some intraspecific variation is evident regarding which of the trunks merge into the ventral vessel.

\section{Arterial Supply of Central Nervous System}

A fine meshwork of intraganglionic arteries is evident in Hadrurus arizonensis arizonensis. These arteries are minute compared to the main vessels. Nine transganglionic arteries can be observed in Diplocentrus lindo, and appear to be especially long, protruding far ventrally and branching distally back into the ventral nerve mass (Fig. 5C; tgl). The supply of the ventral nerve mass is also maintained by single arteries branching off the base of the pedal and pedipalpal arteries, respectively. These vessels continue medially and branch inside the ganglia.

\section{Comparison of the Anterior Aorta Major Branching Patterns}

The distribution of the major arteries branching off the aorta differs among the species studied (compare Fig. 2C,D with Fig. 5B,D; see Table 1 in discussion section). Two patterns can be distinguished, hereafter referred to as Anterior Aorta Major Arterial Branching Pattern 1 (AP1; Fig. 6A) and Anterior Aorta Major Arterial Branching Pattern 2 (AP2; Fig. 6B). In AP1, the cheliceral arteries branch off before the aorta splits from a common trunk. Thereafter, the aorta splits into two large trunks which curve backwards around the esophagus. The pedipalpal arteries branch off anteriorly at the bends. The arteries for the first walking legs emanate from almost the same point and continue in a ventro-lateral direction in most species. However, in Lychas mucronatus, these arteries split off a short way along the pedipalpal arteries so that both the pedipalpal arteries and the arteries of the first walking legs possess a common trunk. After both aortic trunks have turned in a posterior direction, they produce three pairs of arteries for the second to fourth pairs of walking legs. The two trunks of the 
aorta bend inwards, behind the point where the arteries of the fourth pair of walking legs branch off, and unite to form the supraneural ventral vessel. AP2 differs from AP1 in three respects (compare Fig. 6A,B). Firstly, the cheliceral arteries branch off after the split of the aorta and thus do not possess a common trunk. Secondly, the aortic trunks merge directly into the pedipalpal arteries which are similar in diameter. The arteries of the first and second pairs of walking legs branch off from the proximal part of the pedipalpal arteries. Thirdly, the two aortic trunks do not unite after bending backwards and only one of the branches continues posteriorly as a supraneural vessel directly above the ventral nerve cord. However, in Brotheas granulatus the two trunks of the aorta unite to form the supraneural artery.

\section{DISCUSSION \\ Comparative Morphology of Vascular System in Scorpiones}

The above descriptions agree favorably with previous studies on the morphology of the circulatory system in Scorpiones. The general pattern of the HVS among the different species is similar (summarized in Fig. 3A). A dorsal, pulsatile heart is extended posteriorly by a posterior aorta through the metasoma into the telson. The heart is equipped with pairs of incurrent ostia and cardiac arteries. The heart merges anteriorly with the anterior aorta, which presents a complicated branching pattern in the prosoma. Branches from these vessels supply the body appendages and tissues in the prosoma. A supraneural ventral vessel extends from the posterior part of the anterior aorta, between the gut and the ventral nerve cord, to supply ganglia in the meso- and metasoma.

Despite gross similarities in the circulatory system of the taxa studied, there are some important differences, discussed below.

The heart. The gross anatomy of the heart is very similar in the scorpion species that have been studied (Newport, 1843; Petrunkevitch, 1922; Soares, 1950; Randall, 1966; this study). The heart extends the entire length of the mesosoma and comprises spirally-arranged semicircular muscle fibers. These muscle fibers are arranged obliquely in the Buthidae (Randall 1966; this study: Fig. 1C) whereas, in two non-buthids, Uroctonus mordax (Randall, 1966) and Hadrurus arizonensis arizonensis (this study), the musculature is arranged perpendicular to the body axis. A sac-like pericardium surrounds the entire heart (e.g., Randall, 1966). The presence of seven pairs of pulmono-pericardial sinuses (Dubuisson, 1925; see also Gruner, 1993) could not be confirmed. Casts clearly show the presence of four pairs of sinuses (Fig. 1F).

Ostia. Seven pairs of ostia were observed in all species examined for the present study and have also been described in most scorpion species previously studied (Petrunkevitch, 1922; Soares, 1950; Randall, 1966). Newport (1843), however, described the heart as comprising eight consecutive heart chambers, each equipped with a pair of ostia and a pair of cardiac arteries. The chambered nature of the heart is implausible as no structures exist which could separate the heart into different chambers, (see Figs. 1C, 5A; Randall, 1966). Randall (1966) nonetheless remarked that he could not exclude the presence of a further (eighth) pair of ostia in the anterior part of the heart in the first "preabdominal" segment, because of the presence of a pair of cardiac arteries in this region (see also Fig. 1C; ca1). This additional pair of ostia could not be found in either the histological sections (Fig. 1A; inset) or the casts (Figs. 1C, 5A) prepared for the present study. We are therefore convinced that only seven pairs of ostia exist in scorpions.

Cardiac arteries. Eight pairs of cardiac arteries emanate from the heart in most scorpion species that have been studied. These vessels are equipped with valves at their origin to prevent hemolymph flow back into the heart during the systole. Randall (1966) described eight pairs of cardiac arteries in Centruroides sculpturatus (Buthidae), but observed only six in Uroctonus mordax (Vaejovidae).

Anterior aorta system. In all scorpion species studied so far, the anterior aorta splits into two lateral branches just above the esophagus. The two branches are here considered to be real vessels and not "thoracic sinuses" (e.g., Petrunkevitch, 1922; Firstman, 1973) because they are prolongations of the aorta, surrounded by a membrane.

Concerning the anterior aorta major branching patterns, type AP1 (Fig. 6A) has been observed in all buthid species studied so far (Randall 1966; this study), as well as all vaejovid species, and Superstitionia donensis (Superstitioniidae) (see also Table 1).

AP2 has been observed in several other nonbuthid scorpions (Fig. 6B; see also Table 1), including the chactid, iurid, diplocentrid, liochelid, and scorpionid species examined for this study, two Urodacus species (Urodacidae) studied by Locket (2001), and a Euscorpius species (Euscorpiidae) studied by Schneider (1892). Several of these observations on the cheliceral arteries and the origin of the supraneural vessel were previously noted in three Urodacus species by Locket (2001), who described them as asymmetries in the circulatory system. However, based on our observations, Locket's (2001) perceived asymmetries in fact conform to AP2, which has been observed in several nonbuthid scorpion families besides Urodacidae.

\section{Arterial Supply of Central Nervous System in Arthropods}

Schneider (1892) first demonstrated the presence of transganglionic arteries in the ventral nerve 
mass of scorpions. However, his descriptions of 10 transganglionic arteries cannot be corroborated. In the casts prepared for the present study, only nine transganglionic arteries were observed (see Fig. 4A), a number that corresponds exactly to the number of nerves which exit the thoracic nerve mass (cf. Hjelle, 1990): a pair of pedipalpal nerves; four pairs of pedal nerves; four pairs of mesosomal nerves. Petrunkevitch (1922) also described nine transganglionic arteries but did not mention the fine meshwork of small vessels in the central nerve masses. Therefore, although previously demonstrated (Petrunkevitch, 1922; Lane et al., 1981; Locket, 2001), our study visualizes the three-dimensional complexity of this system for the first time (Figs. 4B-E, 5B-D).

Lane et al. (1981) investigated the structure of the walls of the transganglionic and intraganglionic arteries ultrastructurally and electrophysiologically, and revealed that these arteries are true vessels because they are surrounded by an endothelial cell layer and a basement membrane. These authors further demonstrated that a complex blood-brain barrier occurs between the vessels and the central nerve masses. This blood-brain barrier appears to be of comparable complexity to the blood-brain barriers of vertebrates and not as perforated as those observed in Crustacea (Lane et al., 1981).

In general, the direct hemolymph supply of the CNS appears to be required by all animals in which oxygen is distributed via the hemolymph, as evidenced by similar vascular systems described in other chelicerates (e.g., Paul et al., 1994), Crustacea (e.g., Sandemann, 1967), and Scutigeromorpha (Chilopoda, Myriapoda; Wirkner and Pass, 2002).

\section{Complex Open Circulatory System in Euarthropods}

Corrosion-casting is a useful technique for modern studies of the vascular system, the applications of which have been extensively demonstrated among a selection of invertebrates in recent years (Locket, 2001; McGaw and Reiber, 2002; McGaw, 2005; Wirkner and Richter, 2007). Very complex three-dimensional vascular structures can be readily visualized using this technique in combination with SEM. The combination of injection methods with modern noninvasive and nondestructive techniques such as MicroCT is a further advancement (see also Wirkner and Richter, 2004).

All these methodological advances have greatly enhanced our understanding of the architecture and function of the circulatory system of arthropods. Although the circulatory system of euarthropods was once believed to be rather simple (e.g., Gruner, 1993; Brusca and Brusca, 2003), we now know that complex arterial systems, of comparable complexity to the arterial systems of vertebrates, prevail in at least three major groups, Chelicerata, Myriapoda and Malacostraca. Even in hexapods with a reduced arterial system, i.e., HVS (Jones, 1977), this reduction is compensated by a great diversity of so-called accessory pulsatile organs, addressing the need to supply diverse appendages and tissues (Krenn and Pass, 1993; Pass, 1998, 2000). Not only do the vascular structures display a high level of organization, but the non-vascular or lacunar parts of the circulatory system do so as well. As with the vascular structures, corrosion-casting methods, in particular, demonstrate that the pathways taken by the hemolymph back to the pericardial sinus are distinct and can be traced repeatedly in different specimens and taxa. Examples include the complex venous hemolymph pathways of terrestrial crabs (e.g., Greenaway and Farrelly, 1984), the podo-pericardial sinuses of assorted malacostracan Crustacea (e.g., Wirkner and Richter, 2007; in press), and the book lung sinuses of Scorpiones (Fig. 1F; ps). Additionally, the functional organization, i.e., physiology of the circulatory system, especially in those taxa with an elaborated HVS, also reveals a high level of complexity (e.g., McMahon and Burnett, 1990 and literature therein). Indeed, this high level of organization has prompted some researchers to suggest that this complex circulatory system can no longer be termed "open" but "partially closed" or something intermediate (e.g., Paul et al., 1994; McGaw and Reiber, 2002; McGaw, 2005). Others point out, however, that the term "open" (e.g., Maynard, 1960; McMahon and Burnett, 1990) does not refer to the level of organization of the circulatory system but rather to its ontogenetic development as, in all arthropods, the primary and secondary body cavities fuse during ontogeny by mixocoely (see Jones, 1977; Scholtz, 2002; Mayer et al., 2004 and literature in therein), the resulting body fluid being termed hemolymph (as opposed to blood, being contained in a closed vascular system, e.g., in Annelida; Gruner, 1993). Furthermore, no evidence exists to suggest that the HVS is a closed system in any arthropod species studied. All true arteries, i.e., tubular structures connected with the central pumping structure (i.e. heart) and surrounded by a membrane, are open-ended, allowing the hemolymph to re-enter the mixocoel. The so-called "veins" described for scorpions (e.g., Dubuisson, 1925) are membranous structures which return the hemolymph to the pericardium rather than the heart proper. Their membranes are confluent with the membrane of the pericardium. Therefore, we strongly advocate use of the term "open" for the general type of circulatory system in Arthropoda. The demonstrated complexity of this system, however, will hopefully stimulate further studies of its fascinating structure and function.

\section{ACKNOWLEDGMENTS}

CSW spent 8 weeks at the Division of Invertebrate Zoology, American Museum of Natural His- 
tory (AMNH), supported by an Annette-Kade-Fellowship. We thank Erich Volschenk and Randy Mercurio (AMNH) for help in the lab and Bernhard Heneka (RJL Micro and Analytic GmbH, Karlsdorf-Neuthard, Germany) for help with MicroCT. Rommy Petersohn helped with histology, Martin Stegner with the preparation of the figure plates. Nikolaus Urban Szucsich helped to improve the manuscript. The detailed comments of an anonymous reviewer are gratefully acknowledged.

\section{LITERATURE CITED}

Babu KS. 1965. Anatomy of the central nervous system of arachnids. Zool Jb Anat 82:1-154.

Brusca RC, Brusca GJ. 2003. Invertebrates, 2nd ed. Sunderland: Sinauer Associates.

Ch'en-Pin P. 1940. Morphology and anatomy of the Chinese scorpion Buthus martensi Karsch. Peking Nat Hist Bull 14:103-117.

Coddington JA, Giribet G, Harvey MS, Prendini L, Walter DE. 2004. Arachnida. In: Cracraft J, Donoghue MJ, editors. Assembling the Tree of Life. Oxford, New York: Oxford University Press. pp 296-318.

Dubuisson M. 1925. Recherches sur la circulation sanguine et le ventilation pulmonaire chez le Scorpions. Bull Acad Roy Belgique 11:666-680.

Farley RD. 1999. Scorpiones. In: Harrison FW, Foelix RF, editors. Microscopic Anatomy of Invertebrates. New York: WileyLiss. A Chelicerate Arthropoda, Vol 8, pp 117-222.

Firstman B. 1973. The relationships of the chelicerate arterial system to the evolution of the endosternite. J Arachnol 1:154.

Greenaway P, Farrelly CA. 1984. The venous system of the terrestrial crab Ocypode cordimanus (Desmarest, 1825) with particular reference to the vasculature of the lungs. J Morphol 181:133-142.

Gruner HE. 1993. Crustacea. In: Gruner HE, editor. Arthropoda (ohne Insecta). Lehrbuch der Speziellen Zoologie. Bd. I, 4. Teil. Jena: Gustav Fischer.

Hilken G. 1994. Pepsin-mazeration. Eine Methode zur Herstellung von Präparaten für die Rasterelektronenmikroskopie. Mikrokosmos 83:207-209.

Hjelle JT. 1990. Anatomy and morphology. In: Polis GA, editor. The biology of scorpions. Stanford, California: Stanford University Press. pp 9-63.

Jones JC. 1977. The Circulatory System of Insects. Springfield, Illinois: Thomas C.C. 255 p.

Krenn HW, Pass G. 1993. Wing-hearts in Mecoptera (Insecta). Int J Insect Morphol Embryol 22:63-76.

Lamoral BH. 1980. A reappraisal of the suprageneric classification of recent scorpions and their zoogeography. In: Gruber J, editor. Verhandlungen des 8. Internationalen Arachnologenkongress. Wien: H. Egermann. pp 439-444.

Lane NJ, Harrison JB, Bowermann RF. 1981. A vertebrate-like blood brain barrier, with intraganglionic blood channels and occluding junctions in the scorpion. Tissue Cell 13:557576.

Locket NA. 2001. Asymmetries in the arterial system of some Australian Urodacus Peters, 1861 (Scorpiones: Urodacidae). Scorpions 2001. In: Fet V, Selden PA, editors. Memoriam Gary A. Polis. Bunham Beeches, Bucks: British Arachnological Society. pp 343-348.

Mayer G, Ruhberg H, Bartolomaeus T. 2004. When the epithelium ceases to exist-An ultrastructural study on the fate of the embryonic coelom in Epiperipatus biolleyi (Onychophora, Peripatidae). Acta Zool 85:163-170.
Maynard DM. 1960. Circulation and heart function. In: Waterman TH, editor. The Physiology of Crustacea. New York: Academic Press. pp 161-226.

McGaw IJ. 2005. The decapod crustacean circulatory system: A case that is neither open nor closed. Microsc Microanal 11: 18-36.

McGaw IJ, Reiber CL. 2002. Cardiovascular system of the blue crab Callinectes sapidus. J Morphol 251:1-4.

McMahon BR, Burnett LE. 1990. The crustacean open circulatory system: A reexamination. Physiol Zool 63:35-71.

Newport G. 1843. On the structure, relations and development of the nervous and circulatory systems in Myriapoda and macrurous Arachnida. Philos Trans R Soc Lond Biol Sci 271-302.

Pass G. 1998. Accessory pulsatile organs. In: Harrison FH, Locke M, editors. Microscopic Anatomy of Invertebrates. New York: Wiley-Liss. Insecta, Vol 11B, pp 621-640.

Pass G. 2000. Accessory pulsatile organs: Evolutionary innovations in insects. Annu Rev Entomol 45:495-518.

Paul R, Bihlmayer S, Colmorgan M, Zahler S. 1994. The open circulatory system of spiders (Eurypelma californicum, Pholcus phalangoides): A survey of functional morphology and physiology. Physiol Zool 67:1360-1382.

Pawlowsky EN. 1922. Zur mikroskopischen Anatomie des Blutgefässystems der Skorpione. Acta Zool 3:461-474.

Petrunkevitch A. 1922. The circulatory system and segmentation in Arachnida. J Morphol 36:157-185.

Prendini L. 2000. Phylogeny and classification of the superfamily Scorpionoidea Latreille, 1802 (Chelicerata, Scorpiones): An exemplar approach. Cladistics 16:1-78.

Prendini L, Wheeler WC. 2005. Scorpion higher phylogeny and classification, taxonomic anarchy, and standards for peer review in online publishing. Cladistics 21:446-494.

Randall WC. 1966. Microanatomy of the heart and associated structures of two scorpions. Centruroides sculptaturus Ewing and Uroctonus mordax Thorell. J Morphol 119:161-180.

Sandemann DC. 1967. The vascular circulation in the brain, optic lobes and thoracic ganglia of the crab Carcinus. Proc $\mathrm{R}$ Soc Lond B Biol Sci 168:82-90.

Schneider A. 1892. Sur le systeme artériel du scorpion. Tab Zool 2:157-198.

Scholtz G. 2002. The Articulata hypothesis-Or what is a segment? Org Divers Evol 2:197-215.

Soares BAM. 1950. Sobre o coraçao, o sistema nervoso estomato-gastrico e a circulaçao cardiaca nos escorpioes de genero Tityus C.L. Koch 1836. Bol Fac Fil Sao Paulo 15:239-269.

Soleglad ME, Fet V. 2003. High-level systematics and phylogeny of the extant scorpions (Scorpiones: Orthosterni). Euscorpius 11:1-175.

Stockwell SA. 1989. Revision of the phylogeny and higher classification of scorpions (Chelicerata), PhD Dissertation, University of California.

Tjønneland A, Økland S, Midttun B. 1985. Myocardial ultrastructure in five species of scorpions (Chelicerata). Zool Anz 214:7-17.

Wirkner CS, Pass G. 2002. The circulatory system in Chilopoda: Evolutionary and phylogenetic aspects. Acta Zool 83:197-202.

Wirkner CS, Richter S. 2003. The circulatory system in Phreatoicidea: implication for the isopod ground pattern and peracarid phylogeny. Arthropod Struct Dev 32:337-347.

Wirkner CS, Richter S. 2004. Improvement of microanatomical research by combining corrosion casts with MicroCT and 3D reconstruction, exemplified in the circulatory organs of the woodlouse. Microsc Res Tech 64:50-54.

Wirkner CS, Richter S. The circulatory system and its spatial relations to other major organ systems in Spelaeogriphacea and Mictacea (Malacostraca, Crustacea)-A three-dimensional analysis. Zool J Linn Soc (in press).

Wirkner CS, Richter S. 2007. The circulatory system in Mysidacea-Implications for the phylogenetic position of Lophogastrida and Mysida (Malacostraca, Crustacea). J Morphol (in press). 